\title{
REFLEXÕES SOBRE O ENSINO DE ARTES/MÚSICA \\ NA EDUCAÇÃO BÁSICA NO ATUAL CENÁRIO
}

\author{
Lucian José de Souza Costa \\ UEPA \\ Áureo Déo DeFreitas Júnior \\ UFPA
}

\section{Resumo}

Este trabalho é um recorte de pesquisa de mestrado que teve como objetivo investigar como ocorre a formação inicial e continuada dos professores de Artes/música na Educação Básica na Use 11. Neste recorte apresentamos o ensino de artes/música no atual contexto de algumas escolas da região metropolitana de Belém. Esta pesquisa desenvolvese por meio de um estudo bibliográfico e de um estudo de caso. A metodologia aplicada parte de um levantamento bibliográfico preliminar sobre os assuntos, envolvendo o tema desta pesquisa, realizado em fontes infográficas, posteriormente, foi feita a leitura dos textos, com base nas orientações de Severino (2007), e o método escolhido foi o Estudo de Caso. Os resultados permitem verificar que os profissionais da área de Artes, com habilitação no ensino de Música, são direcionados após sua formação acadêmica a lecionar aulas ao ensino fundamental e médio, sendo que no curso de formação não há uma visão clara do que realmente se pode esperar no campo de atuação.

\section{Palavras-chave:}

Educação básica; Ensino de música; Artes/música.

\section{INTRODUÇÃO}

A Arte é um importante trabalho educativo, pois procura, através das tendências individuais, amadurecer a formação do gosto, estimular a inteligência e contribuir para a formação da personalidade do indivíduo, sem ter como preocupação única e mais importante a formação de artistas. No seu trabalho criador, o indivíduo utiliza e aperfeiçoa processos que desenvolvem a percepção, a imaginação, a observação e o raciocínio. No processo de criação, ele pesquisa a própria emoção, libertase da tensão, ajusta-se, organiza pensamentos, sentimentos, sensações e forma hábitos de trabalho.

\section{Abstract}

This work is an excerpt of a master's research that aimed to research how the initial and continuing training of Arts / music teachers in Basic Education in Use occurs 11. In this excerpt we present the teaching of arts / music in the current context of some schools in the city. metropolitan area of Belém. This research is published through a bibliographic study and a case study. The applied methodology of a preliminary bibliographic survey on the subjects, involving the theme of this research, carried out in infographic sources, was subsequently read through the texts, based on the guidelines of Severino (2007), and the method chosen was the Study of Case. The results allowed to verify that the professionals of the area of Arts, with qualification in the teaching of music, are directed after their academic formation to classes to the elementary and high school, being that in the formation course there is not a clear vision of what can really be expected in the field.

Keywords:

Basic education; Music teaching; Arts/music.

Na proposta geral dos Parâmetros Curriculares Nacionais, Arte tem uma função tão importante quanto a dos outros conhecimentos no processo de ensino e aprendizagem. A área de Arte está relacionada com as demais áreas e tem suas especificidades. A educação em arte propicia o desenvolvimento do pensamento artístico e da percepção estética, que caracterizam um modo próprio de ordenar e dar sentido à experiência humana: o aluno desenvolve sua sensibilidade, percepção e imaginação, tanto ao realizar formas artísticas quanto na ação de apreciar e conhecer as formas produzidas por ele e pelos colegas, pela natureza e nas diferentes culturas (BRASIL, 1997, p. 19).

Ana Mae Barbosa (2003) menciona que é também por meio da Arte que a pessoa desenvolve a 
percepção e a imaginação, aprende a realidade do meio ambiente, desenvolve a capacidade crítica, permitindo ao indivíduo analisar a realidade percebida e desenvolver a criatividade de maneira a mudar a real idade, que foi analisada.

Para Zagonel (2008, p. 38), “o ensino da arte não se encerra na escola, nem com relação aos conhecimentos, nem quanto às habilidades adquiridas. Ele deve ser forte e profundo o suficiente para que o leve para sua vida toda [...]". Cunha (2010, p. 91) discorre que desenvolver o pensamento criativo passou a ser uma meta prioritária na preparação para o futuro, visto que os conhecimentos adquiridos hoje podem não valer nada amanhã.

Podem-se destacar as políticas públicas e de que maneira tem contribuído na organização de políticas do ensino da arte escolar para atuar na educação básica, bem como as políticas para a formação de professores em arte para atuar na educação básica (Art. 22). A educação básica tem por finalidades desenvolver o educando, assegurar-lhe a formação comum indispensável para o exercício da cidadania e fornecer-lhe meios para progredir no trabalho e em estudos posteriores (BRASIL, 2017, p. 17).

Com a Lei n. 9.394/96, Arte é considerada disciplina obrigatória na educação básica: “o ensino da arte constituirá componente curricular obrigatório, nos diversos níveis da educação básica, de forma a promover o desenvolvimento cultural dos alunos" (art. 26, §20). Já no inciso§ $2^{\circ}$ a Lei de Diretrizes e Bases descreve a seguinte norma: o ensino da arte, especialmente em suas expressões regionais, constituirá componente curricular obrigatório da educação básica.

Também alude-se ao fato de que os Parâmetros Curriculares Nacionais (PCN), elaborados pelo Ministério da Educação como propostas pedagógicas, também não contribuem para uma definição concreta sobre como a música deve ser trabalhada em sala de aula e não definem se o professor de arte deve ter uma formação geral, com o conhecimento das várias linguagens artísticas, ou se deve ser especializado em uma só modalidade (teatro, dança, música ou artes visuais), conforme comentam Penna (2004) e Arroyo (2004). A tudo isso se soma a defasagem cultural em que vivemos, dificultando uma compreensão para um ensino da arte eficaz e global (FUCCI AMATO, 2006, p. 154).

Neste sentido, é quase inevitável falar de Educação Básica sem falar do Ensino Superior, em especial dos Cursos de Licenciatura. [...], mas ambas, Educação Básica e Educação Superior estão imbricadas e comprometidas mutuamente (NUNES, 2006, p. 02).

O ensino de artes na educação básica abrange outras linguagens que se constituem como disciplinas, a saber: $\S 60$ As artes visuais, a dança, a música e o teatro são as linguagens que constituirão o componente curricular de que trata o § 20 deste artigo. (BRASIL, 2017, p.19). Cada uma das linguagens está prevista em lei o que assegura que o professor de artes, não apenas ministrará sua linguagem de formação, mas abrangerá as outras linguagens de forma a conciliar o que está regulamentado nas leis de Diretrizes e Bases.

A arte na educação básica não tem por finalidade a formação de artistas, e sim a apreciação e o pleno conhecimento do fazer, e do pensar dentro de uma sociedade elementos constitutivos não só de paisagens, mais de sons, e do próprio olhar cotidiano. A partir desse contexto, constata-se que:

Com relação aos conteúdos, orienta-se o ensino da área de modo a acolher a diversidade do repertório cultural que a criança traz para a escola, a trabalhar com os produtos da comunidade na qual a escola está inserida e também que se introduzam informações da produção social a partir de critérios de seleção adequados à participação do estudante na sociedade como cidadão informado (BRASIL, 1997, p.37).

Além deste fragmento pautado pelos PCN, podemos observar o envolvimento dos alunos com a disciplina de Artes a partir de seu contexto local, regional e até mesmo nacional. $\mathrm{O}$ ato de criar tem por sua vez sua particularidade, no que olham no que ouvem e no que sentem a respeito de mundo, tudo parte de uma perspectiva mais próxima de suas vivências em sociedade, observa-se:

Além disso, a arte nem sempre se apresenta no cotidiano como obra de arte. Mas pode ser observada na forma dos objetos, no arranjo de vitrines, na música dos puxadores de rede, nas ladainhas entoadas por tapeceiras tradicionais, na dança de rua executada por meninos e meninas, nos pregões de vendedores, nos jardins, na vestimenta, etc. O incentivo à curiosidade pela manifestação artística de diferentes culturas, por suas crenças, usos e costumes, pode despertar no aluno o interesse por valores diferentes dos seus, promovendo o respeito e o reconhecimento dessas distinções; ressalta-se assim a pertinência intrínseca de cada grupo e de seu conjunto de valores, possibilitando ao aluno 
reconhecer em si e valorizar no outro a capacidade artística de manifestar-se na diversidade (BRASIL, 1997, p. 37).

O ensino de arte na educação básica tem seus desafios. Um deles diz respeito a polivalência. 0 ensino era vinculado apenas há um professor que tinha que dominar as demais linguagens. Tudo parte de que as próprias instituições de ensino em seus cursos de formação faziam menção à uma arte "centralizada" vinculada ao profissional polivalente, em que o mesmo não tinha a perspectiva e o olhar sobre as outras linguagens. Por exemplo, vale ressaltar:

A complexidade que se gerou a partir da Lei 9394/96, parece evidente. Então as Políticas Públicas no ensino da arte para a Educação Básica, trazem uma problemática de ordem conceitual e estrutural. Para alguns superou-se a Polivalência, para outros ela está latente, não só na Escola Básica, mas ainda em alguns Cursos de Licenciatura do Ensino Superior, que ainda estão em fase de transição na sua adequação a legislação atual, entretanto isto está tencionando ideias, práticas e posições (NUNES, 2006, p. 02).

Nesse caso, percebemos no contexto atual cursos superiores com formação especifica em dança, teatro, artes visuais e música. Estes profissionais atuantes no mercado vão se deparar com esta situação incoerente à sua formação, pois o professor de Arte pode ser qualquer um desses mencionados anteriormente, e não deveriam ter por obrigação o conhecimento de outras linguagens voltando-se novamente para polivalência, mas sim aplicar o conhecimento específico da sua formação de origem.

Observa-se, no seguinte fragmento abaixo, a concordância do termo professor polivalente versus professor de uma linguagem especifica no que diz respeito ao cenário atual da educação básica:

Mesmo que em alguns pontos o Ensino de Arte
tenha avançado, ainda é muito forte a polivalência
na Educação Básica, e, é possível afirmar, através
de dados de pesquisa ,que o Ensino de Arte em
sua nomenclatura na Lei de Diretrizes Nacional
atual, avançou porque denomina conceitualmente
como disciplina e não como atividade, entretanto
a sua nomenclatura e concepção parece que não
ultrapassou o espírito da Polivalência, sendo que
na prática, sistematiza, não a interdisciplinaridade,
mas a polivalência do professor que ainda na
maioria das escolas esta atuando com um ensino
polivalente, em que o professor é levado a assumir
o ensino das Artes Visuais, da Música, do Teatro
e da Dança e num período de cinquenta minutos por semana, ou máximo duas aulas de cinquenta minutos e agora assumindo as quatro linguagens da arte, na escola (NUNES, 2006, p. 02).

Para que o ensino de Arte na educação básica seja gradativo e principalmente organizado de forma que os alunos compreendam cada linguagem, faz-se necessário que os cursos de formação de nível superior em consonância com as politicas públicas em vigor tracem metas para educação básica vinculada ao ensino de artes, para que cada profissional assuma sua "identidade" na sua linguagem de formação e evite ministrar aulas de outras linguagens que comprometem seu processo acadêmico e profissional.

\begin{abstract}
Atualmente o ensino de Artes Visuais, Música, Teatro e Dança, precisa ser revisitado tendo como parâmetro a realidade da práxis do ensino desses conhecimentos específicos nas escolas e no ensino superior também. Isto porque ao criar novos Cursos de Licenciatura, implanta-se em Arte/Educação onde em 4 anos forma, ainda que argumentam que não, o professor polivalente, com um mínimo de formação dos conhecimentos de cada linguagem da arte, argumentando que - acadêmico precisa dessa formação pois a escola exige deste futuro professor, que atue nas quatro linguagens da arte destacadas pela Lei 9394/96(1996) (NUNES, 2006, p. 05).
\end{abstract}

Dentro de uma perspectiva de avaliação, no ensino de artes para a educação básica, os parâmetros curriculares nacionais propõem conteúdos específicos e sugestões de avaliações para cada linguagem da Arte. Além disso, os PCN de Arte são meios de consulta que podem nortear $\mathrm{O}$ trabalho do professor, servindo como um suporte para a reflexão, que pode possibilitar mudanças qualitativas na ação do professor em sala de aula.

Neste sentido, a linguagem desta pesquisa é o ensino de Arte/música que se propõe observar e comparar meios de articulação desta linguagem do professor ao aluno. Enquanto não mudar a estrutura pedagógica das escolas isso continuará a ser um problema.

\section{A RELAÇÃO ENTRE ESCOLAS ESPECIALIZADAS E ESCOLAS DE EDUCAÇÃO BÁSICA}

O ensino de música tem papel fundamental na sociedade, esteve e está presente nos dias atuais. A música é uma forte ligação em contextos mais específicos como as escolas especializadas, os famosos conservatórios de música. No que se 
refere à educação musical no contexto do ensino regular, possui importância no aspecto de ensino. Muitos professores tiveram suas vivências musicais em escolas especializadas na sua maioria.

O texto discorre primeiramente sobre o ensino da música em escolas especializadas e, em seguida, o ensino de música em escolas de educação básica. Existe uma relação proximal entre os dois contextos de ensino, pois professor da educação básica que ensina Arte com formação especifica em música, possivelmente tem seu estudo pautado em conservatórios ou escola de música especializada e posteriormente apresenta aspectos desses lugares em sala de aula na educação básica. A trajetória da educação musical perpassa por várias épocas e períodos, encontrando aspectos e concepções de formação inicial e continuada de professores de artes/música no contexto amazônico.

O que hoje chamamos de Artes antes era educação artística, tendo outras linguagens envolvidas, como a: Dança, Teatro e Artes visuais, mas, para o nosso foco da pesquisa, colocamos em pauta o ensino de Artes/música como forma de estabelecer um direcionamento para o processo investigativo por meio de acervos e memórias de educação em Belém do Pará.

Sendo assim, todo caminho construído, remonta por meio de acervos e memórias de outros períodos presentes na sociedade paraense, mas que influenciaram no futuro, implicando numa formação de qualidade dos professores de artes/Música, dando continuidade em seu trajeto profissional.

Os caminhos dessa educação que implicam no processo de formação continuada, vão desde a educação de forma ampla no contexto paraense, passando pela educação musical especificamente e chegando ao ensino das artes dentro de sala de aula.

\section{A LEGISLAÇÃO E SUAS IMPLICAÇÕES NO CURRÍCULO DA ARTE}

A respeito de politicas públicas no campo das artes, tem se visado muito a educação básica de forma a expandir o ensino e seu direcionamento na perspectiva de praticar o contexto escolar. Isso implica na aceitação não apenas de conteúdo, mas de um novo pensar a respeito das artes. Neste caso, se tem discutido as leis, e principalmente o que compete à Lei de Diretrizes e base (LDB).
A legislação alterou seus artigos e incisos no que compete ao campo das linguagens artísticas. Tal mudança afeta o ensino fundamental e médio. Traz implicações para as artes, fazendo com que os professores tenham novas habilidades e tentem se adaptar ao padrão descrito.

Para isso, compete o entendimento acerca de tais mudanças e propostas, bem como do conhecimento das alterações na LDB e sobre o BNCC. Neste item abordamos a relevância da legislação e suas implicações tanto na disciplina de arte como ao professor.

\section{A BASE NACIONAL COMUM CURRICULAR DE ARTE/MÚSICA}

A Base Nacional Comum Curricular (BNCC, 2018, p. 07) é um documento de caráter normativo que define o conjunto orgânico e progressivo de aprendizagens essenciais que todos os alunos devem desenvolver ao longo das etapas e modalidades da Educação Básica, de modo que tenhamassegurados seus direitos de aprendizagem e desenvolvimento, em conformidade com o que preceitua o Plano Nacional de Educação (PNE).

Este documento normativo aplica-se exclusivamente à educação escolar, tal como definido no $\S 1^{\circ}$ do Artigo $1^{\circ}$ da Lei de Diretrizes e Bases da Educação Nacional (LDB, Lei $n^{\circ}$ 9.394/1996), e está orientado pelos princípios éticos, políticos e estéticos que visam à formação humana integral e à construção de uma sociedade justa, democrática e inclusiva, como fundamentado nas Diretrizes Curriculares Nacionais da Educação Básica (DCN).

No Ensino Fundamental, o componente curricular Arte, está centrado nas seguintes linguagens: as Artes visuais, a Dança, a Música e o Teatro. Essas linguagens articulam saberes referentes a produtos e fenômenos artísticos e envolvem as práticas de criar, ler, produzir, construir, exteriorizar e refletir sobre formas artísticas. A sensibilidade, a intuição, o pensamento, as emoções e as subjetividades se manifestam como formas de expressão no processo de aprendizagem em Arte (BNCC, 2018, p. 07).

No que concerne ao ensino da música, o conteúdo se concentra na área de "Linguagens, Códigos e suas Tecnologias" (BRASIL, 2011) integrando-se 
à esta área como disciplina de arte, considerada importante, pois "o ensino das artes é entendido como conhecimento organizado e sistematizado que propicia aos educandos a criação e a recriação dos saberes artísticos e culturais" (BRASIL, 2016, p. 517).

Sendo assim, ao garantir o direito ao aluno de receber ensino de música na escola, como conteúdo obrigatório, mas não exclusivo como prevê a Lei № 11769/2008, ainda se inscreve o conteúdo de música integrado à disciplina de arte, como área do conhecimento importante por compor a área "Linguagens, Códigos e suas Tecnologias" (BRASIL, 2011). A Base Nacional Comum Curricular (BNCC) propõe:

\begin{abstract}
A Música é uma expressão humana que se materializa por meio dos sons, que ganham forma, sentido e significado nas interações sociais, sendo resultado de saberes e valores diversos estabelecidos no âmbito de cada cultura. A ampliação e a produção dos conhecimentos musicais passam pela percepção, experimentação, reprodução, manipulação e criação de materiais sonoros diversos, dos mais próximos aos mais distantes da cultura musical do estudante. Na Educação Básica, o processo de formação musical garante ao sujeito o direito de vivenciar música de diferentes maneiras, de modo inter-relacionado à diversidade, desenvolvendo saberes musicais fundamentais para sua inserção e participação crítica e ativa na sociedade. Como forma artística, a música tem potencial para promover o trabalho interdisciplinar, seja com os demais componentes da Arte, seja com outros componentes e áreas do currículo escolar (BRASIL, 2016, p. 522).
\end{abstract}

Nesta perspectiva, o ensino de música por intermédio do novo padrão que é a BNCC, proporciona dentro da disciplina de Arte o contato do aluno por meio de seu contexto e prática, elementos da linguagem, materialidade, notação, registro musical e processos de criação. 0 professor é um professor propositor que pesquisa e compartilha com alunos e busca "novos saberes" que nos nutrem em projetos no ensino e aprendizagem de Arte.

A proposição pedagógica trazida pela BNCC para arte é um convite a alunos e professores para que acessem conhecimentos e experiências com a Arte por muitos meios e situações, em um tempo e cultura repletos de possibilidades sonoras, visuais, audiovisuais e gestuais, tendo como palco o espaço da escola.

Socializando esse "novo tempo" dentro do campo da Arte, vejamos abaixo o quadro demonstrativo na unidade da música, no qual se pode visualizar o ano/faixa, unidade temática: Música, objetos de conhecimento e habilidades. A partir disso, o professor pode atender esta demanda e fazer adaptações em seus conteúdos e utilização de materiais para então atender esta Base Comum Curricular.

\section{DIÁLOGOS E REFLEXÕES A RESPEITO DA DISCIPLINA DE ARTES/MÚSICA EM SALA DE AULA}

Cada aluno tem seu grau de dificuldade, e acaba não assimilando o processo de aprendizagem do conteúdo explicado pelo professor em sala de aula. Toda disciplina tem sua forma de avaliar o aluno e seu desempenho para obtenção de nota em cada bimestre. Tanto o processo de aprendizagem, como de avaliação estão ligados à forma como o professor de música alcança seus alunos e propõe a disciplina.

De acordo com Souza (2000, p. 17), "a tarefa básica da música na educação é fazer contato, promover experiências com possibilidades de expressão musical e introduzir os conteúdos e as diversas funções da música na sociedade, sob as condições atuais e históricas". O professor é o mediador entre conteúdo e aluno, de que forma esse aluno vai receber este conteúdo e como o professor fará para expor de forma objetiva e que o aluno entenda. Cada detalhe no processo de aprendizagem a na forma de avaliar vai sendo construído em sala de aula ao longo dos estudos.

Referindo-se ao processo de aprendizagem, na sala de aula há vários meios de praticar a música, pois há um passo-a-passo na maneira como o professor aplica o conteúdo, a saber: primeiro o professor escolhe o conteúdo na linguagem musical que, por exemplo, pode ser sobre ritmo e explica de forma teórica sobre o assunto, além de adicionar conhecimento acerca de pulso e andamento. Após esse momento, podem ser feitas atividades rítmicas com as cartelas Kodaly e criação de células rítmicas com figuras musicais recortadas e no final deste processo apresentar uma música que envolva essa aprendizagem.

Tratando-se de avaliação, o professor tem "liberdade" em optar pela prova objetiva. Por exemplo, pode ser feita em dupla ou quarteto para trabalhar a percepção rítmica de cada aluno e observar se cada um adquiriu conhecimento com 


\begin{tabular}{|c|c|c|c|c|}
\hline COMPONENTE & ANO/FAIXA & $\begin{array}{l}\text { UNIDADES } \\
\text { TEMÁTICAS }\end{array}$ & $\begin{array}{l}\text { OBJETOS DE } \\
\text { CONHECIMENTO }\end{array}$ & HABILIDADES \\
\hline ARTE & $6^{\circ} ; 7^{\circ} ; 8^{\circ} ; 9^{\circ}$ & Música & $\begin{array}{l}\text { Contextos } \\
\text { e práticas }\end{array}$ & $\begin{array}{l}\text { (EF69AR16) Analisar criticamente, } \\
\text { por meio da apreciação musical, } \\
\text { usos e funções da música em } \\
\text { seus contextos de produção } \\
\text { e circulação, relacionando as } \\
\text { práticas musicais às diferentes } \\
\text { dimensões da vida social, cultural, } \\
\text { política, histórica, econômica, } \\
\text { estética e ética. }\end{array}$ \\
\hline ARTE & $6^{\circ} ; 7^{\circ} ; 8^{\circ} ; 9^{\circ}$ & Música & $\begin{array}{l}\text { Contextos } \\
\text { e práticas }\end{array}$ & $\begin{array}{l}\text { (EF69AR17) Explorar e analisar, } \\
\text { criticamente, diferentes meios } \\
\text { e equipamentos culturais de } \\
\text { circulação da música e do } \\
\text { conhecimento musical. }\end{array}$ \\
\hline ARTE & $6^{\circ} ; 7^{\circ} ; 8^{\circ} ; 9^{\circ}$ & Música & $\begin{array}{l}\text { Contextos } \\
\text { e práticas }\end{array}$ & $\begin{array}{l}\text { (EF69AR18) Reconhecer e } \\
\text { apreciar o papel de músicos e } \\
\text { grupos de música brasileiros e } \\
\text { estrangeiros que contribuíram } \\
\text { para o desenvolvimento de } \\
\text { formas e gêneros musicais. }\end{array}$ \\
\hline ARTE & $6^{\circ} ; 7^{\circ} ; 8^{\circ} ; 9^{\circ}$ & Música & $\begin{array}{l}\text { Contextos } \\
\text { e práticas }\end{array}$ & $\begin{array}{l}\text { (EF69AR19) Identificar e analisar } \\
\text { diferentes estilos musicais, } \\
\text { contextualizando-os no tempo e } \\
\text { no espaço, de modo a aprimorar } \\
\text { a capacidade de apreciação da } \\
\text { estética musical. }\end{array}$ \\
\hline ARTE & $6^{0} ; 7^{\circ} ; 8^{\circ} ; 9^{\circ}$ & Música & $\begin{array}{l}\text { Elementos da } \\
\text { linguagem }\end{array}$ & $\begin{array}{l}\text { (EF69AR20) Explorar e analisar } \\
\text { elementos constitutivos da } \\
\text { música (altura, intensidade, } \\
\text { timbre, melodia, ritmo etc.), por } \\
\text { meio de recursos tecnológicos } \\
\text { (games e plataformas digitais), } \\
\text { jogos, canções e práticas diversas } \\
\text { de composição/criação, execução } \\
\text { e apreciação musicais. }\end{array}$ \\
\hline ARTE & $6^{0} ; 7^{\circ} ; 8^{\circ} ; 9^{\circ}$ & Música & Materialidades & $\begin{array}{l}\text { (EF69AR21) Explorar e analisar } \\
\text { fontes e materiais sonoros } \\
\text { em práticas de composição/ } \\
\text { criação, execução e apreciação } \\
\text { musical, reconhecendo timbres e } \\
\text { características de instrumentos } \\
\text { musicais diversos. }\end{array}$ \\
\hline
\end{tabular}

Quadro 1 - Quadro demonstrativo da disciplina de Artes para educação básica no ensino fundamental maior na unidade temática da Música. Fonte: http://download.basenacionalcomum.mec.gov.br/ 


\begin{tabular}{|c|c|c|c|c|}
\hline COMPONENTE & ANO/FAIXA & $\begin{array}{l}\text { UNIDADES } \\
\text { TEMÁTICAS }\end{array}$ & $\begin{array}{l}\text { OBJETOS DE } \\
\text { CONHECIMENTO }\end{array}$ & HABILIDADES \\
\hline ARTE & $6^{\circ} ; 7^{\circ} ; 8^{\circ} ; 9^{\circ}$ & Música & $\begin{array}{l}\text { Notação } \\
\text { e registro } \\
\text { musical }\end{array}$ & $\begin{array}{l}\text { (EF69AR22) Explorar e identificar } \\
\text { diferentes formas de registro } \\
\text { musical (notação musical } \\
\text { tradicional, partituras criativas } \\
\text { e procedimentos da música } \\
\text { contemporânea), bem como } \\
\text { procedimentos e técnicas de } \\
\text { registro em áudio e audiovisual. }\end{array}$ \\
\hline ARTE & $6^{\circ} ; 7^{\circ} ; 8^{\circ} ; 9^{\circ}$ & Música & $\begin{array}{l}\text { Processos } \\
\text { de criação }\end{array}$ & $\begin{array}{l}\text { (EF69AR23) Explorar e criar } \\
\text { improvisações, composições, } \\
\text { arranjos, jingles, trilhas } \\
\text { sonoras, entre outros, utilizando } \\
\text { vozes, sons corporais e/ou } \\
\text { instrumentos acústicos ou } \\
\text { eletrônicos, convencionais ou não } \\
\text { convencionais, expressando ideias } \\
\text { musicais de maneira individual, } \\
\text { coletiva e colaborativa. }\end{array}$ \\
\hline
\end{tabular}

Quadro 1 - Continuação do quadro demonstrativo da disciplina de Artes para educação básica no ensino fundamental maior na unidade temática da Música. Fonte: http://download.basenacionalcomum.mec.gov.br/

o assunto proposto. A avaliação do bimestre neste caso pode ser uma prova objetiva, na qual a dupla ou quarteto responde perguntas relacionadas ao assunto, depois executava o ritmo na cartela Podal e, por último, cria uma célula rítmica com quatro figuras para então executar.

É importante a construção da avaliação em sala de aula mediante o processo de aprendizagem, pois o aluno fará aquilo que viu, ouviu, e entendeu em sala de aula. O professor, peça fundamental no processo de aprendizagem, dá o caminho de acesso ao conhecimento até então não conhecido pelo aluno. A partir do momento que o aluno começa assimilar a teoria e prática, consegue fazer sozinho o seu ritmo e o associa a outros ritmos ouvidos por ele no cotidiano.

A finalidade do ensino de música na escola, principalmente no ensino fundamental, não é a de transmitir uma técnica particular, mas sim de desenvolver no aluno o gosto pela música e a aptidão para captar a linguagem musical e expressarse através dela, além de possibilitar o acesso do educando ao patrimônio musical que a humanidade vem construindo (CHIQUETO; ARALDI, 2009, p. 06).
Dentro do âmbito escolar, torna-se imprescindível o uso de práticas sociais principalmente em disciplinas que agregam valores e oportunizam a vivência em grupo, como é o caso das artes. Neste sentido, a linguagem da música traz diversas possibilidades para o aluno expandir seu conhecimento e seu olhar sobre o mundo. Quando se entende que uma disciplina não precisa apenas passar um conteúdo, mas viver uma prática social, os alunos praticam e se acostumam-se, no dia-a-dia, a perceber as coisas de uma outra maneira.

A ideia de se ter musicalização na educação básica é para que cada aluno entenda o sentido e o valor da música em sociedade, não é para formar músicos ou muito menos instrumentistas, mas trazer a prática do cotidiano de forma avaliativa e que entendam o conteúdo de forma objetiva, sem pensar em apenas no fazer prova teórica ou decorar um assunto. Além de levar a musicalização para sala de aula, vem aliado a tudo isso, a forma de avaliação feita pelo educador musical mediante a construção de aprendizagem da turma ao longo das aulas. É importante ressaltar que o ensino 
aprendizagem conduzido pelo professor deve ser o mais objetivo e de fácil entendimento para que o aluno consiga chegar à compreensão do assunto, além de propiciar prazer pela disciplina.

Deste modo, a disciplina de artes/música que tem um professor habilitado em música cumpre seu papel de educação musical levando para sala de aula novas propostas de aprendizagem na música aos alunos. Com essa avaliação, muitos alunos aprimoraram a escuta musical e percepção rítmica sem mesmo saberem que possuíam essa prática, mas, pela disciplina, encontraram novos meios de serem avaliados.

É importante dentro da disciplina de artes/música o olhar do professor em relação à aprendizagem e sua avaliação tornando o aluno sensível a música e mostrando novas práticas musicais presentes em seu cotidiano. Depende de cada educador musical em sua qualificação e no preparo de aulas que enriqueçam sua trajetória escolar. Concluise que é importante buscar novos meios de avaliar os alunos não apenas em provas teóricas, mas em provas objetivas que mostram o papel fundamental de cada aluno tanto em sala de aula como em sociedade.

\section{RELAÇÃO DO PROFESSOR DA EDUCAÇÃO BÁSICA COM ENSINO DE PÓS-GRADUAÇÃOO}

No que tange à formação continuada, a LDB define no inciso III, do art. 63, que as instituições formativas deverão manter "programas de formação continuada para os profissionais de educação dos diversos níveis", além de estabelecer no inciso II, art. 67, "que os sistemas de ensino deverão promover aperfeiçoamento profissional continuado, inclusive com licenciamento periódico remunerado para esse fim". Tal perspectiva amplia o alcance da formação continuada, incluindo os cursos de pós-graduação em nível de mestrado e doutorado.

A partir deste exposto, torna-se relevante a formação do professor da educação básica à nível de mestrado e doutorado. A Coordenação de aperfeiçoamento de pessoal de nível superior (CAPES) publica em 10 de janeiro de 2018 o programa de Mestrados Profissionais para Professores da Educação Básica (PROEB), para qualificação de professores da Rede Pública de Educação Básica - Proibi tem por objetivo a formação continuada stricto sensu dos professores em exercício na rede pública de educação básica, em conformidade com a política do Ministério da Educação - MEC, mediante apoio às instituições de ensino superior (IES) ou rede de instituições associadas do País, responsáveis pela implantação e execução de cursos com áreas de concentração e temáticas vinculadas diretamente à melhoria da Educação Básica.

O apoio da CAPES dar-se-á mediante a concessão de bolsas e fomento aos cursos de Mestrado Profissional do proíbe, nas modalidades presencial e a distância, no âmbito do Sistema Universidade Aberta do Brasil - UAB, da seguinte forma:

Objetivos: O PROEB tem como finalidade a melhoria da qualidade do ensino nas escolas da Educação Básica Pública Brasileira, à medida que: Promove a formação continuada de professores das redes públicas de educação, no nível de pósgraduação stricto sensu, nas áreas da Educação Básica Brasileira; Institui uma rede nacional para oferta de programas de mestrados profissionais promovidos por instituições de ensino superior públicas brasileiras de notória tradição na área de formação de professores e que sejam partícipes do Sistema Universidade Aberta do Brasil; Valoriza as experiências advindas da prática do professor ao mesmo tempo que colabora, através dos trabalhos realizados, para o desenvolvimento de materiais e estratégias didáticas que ensejam a melhoria do desempenho de aprendizagem dos alunos; Cria uma rede de reflexão sobre a realidade do Ensino Básico Público Brasileiro apontando perspectivas de mudanças e respostas aos problemas do cotidiano da escola e da sociedade (FUNDAÇÂO CAPES, 2018).

A relação que se criou neste momento foi a formação continuada de professores de artes da educação básica e que sejam do quadro efetivo para a qualificação de seu crescimento profissional, desta maneira, o incentivo ao processo de aprendizagem será intensificado dando oportunidade de continuidade na carreira do magistério.

Projeto do Curso: o curso tem uma estrutura semi-presencial com a oferta de duas disciplinas de fundamentação à distância, quatro disciplinas obrigatórias (incluindo a realização de trabalho de conclusão orientado de forma presencial) e duas optativas. Para participar do Prof-Artes os candidatos deverão ser docentes concursados na Educação Básica (Ensino Fundamental e Ensino Médio), portadores de diploma de nível superior reconhecidos pelo MEC em qualquer área do conhecimento, e devem estar ministrando aulas de artes (Artes Cênicas, Artes Visuais e Música) em Instituições Escolares Públicas. Os candidatos deverão manter sua atividade na escola durante o Mestrado Profissional (UDESC CEART, 2018). 
A CAPES, por meio do ProEB, tem parceria com algumas universidades do país proporcionando esta proposta de formação continuada. A Universidade Federal do Pará criou o PROFARTES, programa de Mestrado Profissional (Stricto sensu) em Artes com área de concentração em Ensino de Artes, reconhecido pela Coordenação de Aperfeiçoamento de Pessoal de Nível Superior (CAPES) do Ministério da Educação. Este curso é oferecido em formato semipresencial com obrigatoriedade de assistência às aulas nos Campi.

Algumas das Instituições de Ensino Superior Associadas neste programa são: Universidade Estadual Paulista (UNESP), Universidade do Estado de Santa Catarina (UDESC); Universidade de Brasília (UnB); Universidade Federal do Ceará (UFC); Universidade Federal da Bahia (UFBA); Universidade Federal do Maranhão (UFMA); Universidade Federal de Minas Gerais (UFMG); Universidade Federal do Pará (UFPA); Universidade Federal da Paraíba (UFPB); Universidade Federal do Rio Grande do Norte (UFRN); Universidade Federal de Uberlândia (UFU).

Com este incentivo, cabe aos professores participarem desse processo de aprendizagem, apesar de ter um processo seletivo, não impede que professores de artes de qualquer linguagem participem. A função principal é tornar comum a todos o ensino aprendizagem de sala de aula e a partir do processo criativo dentro da escola tornese em pesquisas cientificas.

Sendo assim, a relação da formação continuada com os programas de pós-graduação são caminhos para o professor de artes se qualificarem e interagir com sua prática de sala de aula. A presente pesquisa traz essa relação, esse processo, que é gerado na formação inicial e permanece constante à vida toda mediante 0 estimulo do profissional da área.

\section{METODOLOGIA DA PESQUISA}

Esta pesquisa desenvolve-se por meio de um estudo bibliográfico e de um estudo de caso. Para Gil (2008, p. 45), a principal vantagem da pesquisa bibliográfica reside no fato de permitir ao investigador a cobertura de uma gama de fenômenos muito mais ampla do que aquela que poderia pesquisar diretamente. Este autor entende a pesquisa bibliográfica como
Um processo que envolve as etapas: (a) escolha do tema; (b) levantamento bibliográfico preliminar; (c) formulação do problema; (d) elaboração do plano provisório de assunto; (e) busca das fontes; (f) leitura do material; (g) fichamento; (h) organização lógica do assunto; e (i) redação do texto (GIL, 2008, p. 59-60).

Nesta pesquisa, desenvolvem-se somente algumas dessas etapas, visto que abrange também investigação em campo. O levantamento bibliográfico preliminar sobre os assuntos envolvendo o tema desta pesquisa realizou-se em fontes infográficas, das quais se destacam o site da Associação Brasileira de Educação Musical (ABEM). Buscaram-se artigos nas revistas e anais da ABEM, bem como outras revistas cientificas de cunho relevante para a pesquisa. Realizouse a seleção dos artigos a partir da leitura dos respectivos resumos e palavras-chave.

Posteriormente, foi feita a leitura dos textos, com base nas orientações de Severino (2007): definição das unidades de leitura dos textos selecionados, análise textual, análise temática, problematização e síntese pessoal (resumo crítico e de contribuição reflexiva). A síntese pessoal de cada leitura será uma forma de documentação do estudo bibliográfico, uma espécie de fichamento dos textos que fundamentam a pesquisa.

O método escolhido foi o Estudo de Caso, o qual, segundo Trivinos (1987), é "uma categoria de pesquisa cujo objetivo é uma unidade que se analisa profundamente" (p. 133). Esse método consiste no estudo de um único caso, o qual pode ser o estudo de "uma pessoa, mas também o de um grupo, de uma comunidade, de um meio ou então fará referência a um acontecimento especial" (LAVILLE; DIONE, 1999 , p. 155). Conforme afirmam os mesmos autores, o estudo de caso permite ao pesquisador, no decorrer da pesquisa, adaptar seu instrumento para compreender com maior clareza o caso investigado.

Para Yin (2001, p. 09), os estudos de caso representam a estratégia preferida quando se colocam questões do tipo "como" e "por que", quando o pesquisador tem pouco controle sobre os eventos e quando o foco se encontra em fenômenos contemporâneos inseridos em algum contexto da vida real.

\section{CONSIDERAÇÕES FINAIS}

Conforme tem sido discutido e analisado por estudiosos da área, os professores de música na 
atualidade precisam de uma formação consistente que possibilite a eles atuarem de forma contextualizada com as perspectivas da área de educação musical e com a realidade dos múltiplos espaços de ensino e aprendizagem da música.

As Universidades podem pensar em uma conexão com a educação básica, não apenas por estágios ou programas de docência, mais pelo processo formativo do professor desde sua entrada na graduação. Sua vivência musical vai ter uma influência bastante participativa no seu processo de firmação durante o período da graduação. Um dos grandes desafios ligados aos processos formativos de professores está associado à aproximação entre escola e universidade, de modo a promover comunidades colaborativas, envolvendo professores da escola e professores da universidade.

Os profissionais da área de Artes com habilitação no ensino de Música são direcionados após sua formação acadêmica lecionar aulas ao ensino fundamental e médio, sendo que no curso de formação não há uma visão clara do que realmente se pode esperar no campo de atuação, uma vez que o professor precisará de materiais de apoio que darão suporte para seu trabalho, que nem sempre as escolas dispõem.

Considerando a proposta desta pesquisa e seu problema de estudo, pudemos observar que não há uma resolução definitiva para os questionamentos, porém, tivemos uma amostra relevante para contribuição no campo das artes no que diz respeito à formação inicial e continuada.

Diante da proposta da pesquisa e de seus objetivos, observamos que no âmbito da educação básica e com a pesquisa realizada obteve-se uma amostra reduzida, porém relevante para à área da educação musical. Os objetivos foram cumpridos no que resultou em reflexões que trazem inquietações e ao mesmo tempo contribuições.

\section{REFERÊNCIAS}

BARBOSA, Ana Mae (Org.) Inquietações e mudanças no ensino da arte. 2 ed. São Paulo: Cortez, 2003.

BNCC na prática. Equipe educacional da Editora. São Paulo: FTD, 2018.
BRASIL. Ministério da Educação. Compromisso todos pela educação. Brasília: MEC, 2007. Disponível em: <http://portal.mec.gov.br/ arquivos/pdf/diretrizes_compromisso. pdf $>$. Acesso em: jun. 2007.

BRASIL. Presidência da República. Lei no 11.274, de 06 de fevereiro de 2006. Altera a redação dos Arts. 29, 30, 32 e 87 da Lei no 9.394, de 20 de dezembro de 1996, que estabelece as diretrizes e bases da educação nacional, dispondo sobre a duração de 9 (nove) anos para o ensino fundamental, com matrícula obrigatória a partir dos 6 (seis) anos de idade. Disponível em: https://www.planalto. gov.br/ccivil_03/_Ato2004-2006/2006/Lei/ L11274.htm>. Acesso em: mar. 2007.

BRASIL. Secretaria de Educação Fundamental. Parâmetros Curriculares Nacionais: Arte. Brasília: MEC/ SEF, 2011.

Brasil. Diretrizes Curriculares Nacionais Gerais da Educação Básica. Ministério da Educação. Secretaria de Educação Básica. Secretaria de Educação Continuada, Alfabetização, Diversidade e Inclusão. Conselho Nacional da Educação. Secretária de Educação Básica. Diretoria de Currículos e Educação Integral. - Brasília: MEC, SEB, DICEI, 2013.

BRASIL, Base Nacional Comum Curricular: Proposta preliminar, segunda versão revista. Brasília: MEC, CONSED, 2016.

BRASIL. Presidência da República. Lei n`9.394, de 20 de dezembro de 1996. Estabelece as diretrizes e bases da educação nacional. Disponível em: http://www.planalto.gov.br/CCIVIL_03/ LEIS/L9394.htm. Acesso em 01 de abril de 2018.

CHIQUETO, Marcia Rosane; ARALDI, Juciane. Música na educação básica: uma experiência com sons alternativos. Plano de desenvolvimento da escola: 2008/2009.

CUNHA, Nylse Helena Silva. Brinquedoteca. Um mergulho no brincar. Aquariana, 2010.

FUCCI AMATO, Rita de Cássia. Breve retrospectiva histórica e desafios do ensino de música na educação básica brasileira. In: Revista Opus, vol. 12,2006 , p. 144-166.

FUNDAÇÃO CAPES. CAPES, 2018. Mestrados profissionais para professores da educação básica 
- PROERB. Disponível em: https://www.capes. gov.br/pt/educacao-a-distancia/proeb. Acesso em: mai. 2019.

GIL, Antonio Carlos. Como elaborar projetos de pesquisa. São Paulo: Atlas, 2008.

LAVILLE, C.; DIONNE, J. A construção do saber. Belo Horizonte: UFMG, 1999. 340 p.

NUNES, Ana Luiza Ruschel. O ensino de arte na educação básica. In: XVI ConFAEB. Anais... Ouro Preto/MG, 2006, p.1-16.

SOUZA, Jusamara. (org). Música, cotidiano e educação. Porto Alegre: UFRGS, 2000.

TRIVINOS, A. W. S. Introdução à pesquisa em ciências sociais. São Paulo: Atlas, 1987.

UDESC CEART. Universidade do Estado de Santa Catarina, 2018. PROF-ARTES Mestrado Profissional em Artes. Disponível em: https:// www.udesc.br/ceart/profartes/projetodocurso. Acesso em: mai. 2019.

ZAGONEL, Bernadete. Metodologia do ensino de artes: Arte na Educação Escolar. Curitiba: Ibpex, 2008.

YIN, Robert K. Estudo de Caso: Planejamento e métodos I. Porto Alegre: Bookman, 2001.

\section{SOBRE OS AUTORES}

Lucian José de Souza Costa é professor substituto na Universidade do Estado do Pará (UEPA/ Licenciatura em Música) e professor de arte/ música na Secretaria de Educação do Pará (Seduc). Doutorando em Artes pelo Programa de PósGraduação em Artes (PPGARTES/UFPA). Tem experiência na área de Artes e Educação, com ênfase em educação musical e etnomusicologia. É integrante do Laboratório de Etnomusicologia da Universidade Federal do Pará (LabEtno/UFPA) e do Grupo de Pesquisa Transtornos do Desenvolvimento e Dificuldades de Aprendizagem (GP-TDDA/UFPA). E-mail: luciancosta51@yahoo.com.br

Áureo Déo DeFreitas Júnior possui Graduação em Violoncello Performance pela Universidade do Missouri (Columbia, 1989), Mestrado em Violoncello Performance pela Universidade do Estado da Luisiana (Baton Rouge, 1992), e
Doutorado (Ph.D.) em Educação Musical pela Universidade da Carolina do Sul (Columbia, 2005). Atualmente é professor do Instituto de Ciências da Arte da UFPA (ICA), onde ensina no âmbito do Programa de Pós-graduação em Artes (PPGARTES) e da Escola Técnica de Música (EMUFPA). Na extensão universitária, coordena a Orquestra de Violoncelistas da Amazônia (OVA) e o Programa Cordas da Amazônia (PCA). Na pesquisa, coordena o Grupo de Pesquisa Transtornos do Desenvolvimento e Dificuldades de Aprendizagem (GP-TDDA). E-mail: aureo_freitas@yahoo.com 